research article

\title{
Deep dorsal vein embolization with N-butyl-2-cyanoacrylate and lipiodol mixture in venogenic erectile dysfunction: early and late results
}

\author{
Ramazan Kutlu' ${ }^{1}$, Ahmet Soylu ${ }^{2}$ \\ ${ }^{1}$ Department of Radiology, ${ }^{2}$ Department of Urology, Turgut Ozal Medical Center, Inonu \\ University School of Medicine, Malatya, Turkey
}

Background. The aim of the study was to perform and evaluate pelvic venoablation with N-butyl-2-cyanoacrilate (NBCA) and lipiodol injection into the deep dorsal vein for the treatment of 32 patients with venogenic erectile dysfunction.

Methods. A total of 32 patients with the confirmed diagnosis of venogenic erectile dysfunction, with ( $n=15)$ or without $(n=17)$ associated comorbidities were included. Deep dorsal veins were embolized with NBCA and lipiodol mixture. All patients were evaluated using the erectile function domain of the International Index of Erectile Function questionnaire (IIEF) before, at 3 months and 1 year after embolization.

Results. While the post-operative $3^{\text {rd }}$ month scores were increased significantly in all groups $(p<0.001)$, there was a significant decrease at $12^{\text {th }}$ month when compared to that of $3^{\text {rd }}$ month $(p<0.001)$. But this decrease was significantly higher than those of preoperative values $(p<0.001)$. In patients without comorbidities post-operative $3 r d$ and $12^{\text {th }}$ month scores were significantly higher than that of patients with comorbidities $\left(p<0.04\right.$ and $p<0.02$, respectively). Although scores at $12^{\text {th }}$ month were significantly higher compared to preoperative values, patients with comorbidities were dissatisfied with the quality of erection.

Conclusions. Our pelvic venoablation technique was effective short-term. A limitation of this technique is that some patients are not candidates for this procedure due to comorbidites.

Key words: n-Butyl-2-cyanoacrylate; lipiodol; venous impotence; deep dorsal vein; embolization

\section{Introduction}

Erectile dysfunction (ED) is a complex phenomenon which could be related to physi-

Received 3 December 2008

Accepted 14 January 2009

Correspondence to: Associate Prof. Ramazan Kutlu, MD, PhD, Dept. of Radiology, Turgut Ozal Medical Center, Inonu University School of Medicine, Malatya, Turkey; Phone: +90 4223410660 (Extn: 5703, 5720); E-mail: rkutlu@inonu.edu.tr ologic, hormonal, neurologic, and vascular factors., ${ }^{1,2}$ Vascular impotence is defined as the inability to maintain an erection because of the inability to maintain a sufficient volume of blood within the penis to engorge the corpora cavernosa. ${ }^{3}$ This could occur due to either arterial or venous causes. ${ }^{4}$ Although the exact cause of veno-occlusive dysfunction is not known, several pathophysiologic processes like the presence of large venous channels draining 


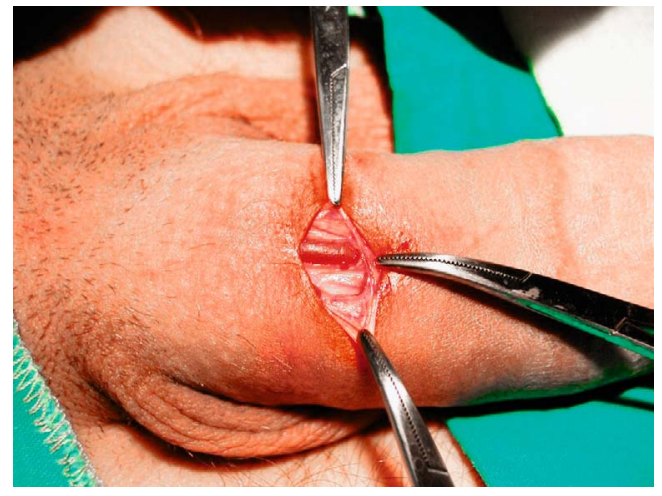

Figure 1a. After local anaesthesia, a small incision was made at the mid penile level and isolated.

the corpora cavernosa, Peyronie's disease, diabetes and structural alterations in the fibroelastic components of the trabeculae, cavernous smooth muscle and endothelium have been mentioned in the literature. ${ }^{5}$

Even though the results of deep dorsal vein embolization (DDVE) are reported to be encouraging, the longer follow-up of these patients is needed. ${ }^{6}$ In this study, we are reporting on early and late followup results of our patients that were treated with DDVE using N-butyl-2-cyanoacrilate (NBCA) and lipiodol injection. Patients suffered from the venogenic erectile dysfunction.

\section{Patients and methods}

A total of 32 patients with the confirmed diagnosis of venogenic erectile dysfunction by penile Doppler ultrasound and cavernosography gave informed consents after the detailed explanation of results, advantages, disadvantages and possible complications of available treatment options (surgical ligation, vacuum device, penile prosthesis implantation, oral and intracavernosal medications and embolization) for DDVE with NBCA and lipiodol mixture. All patients completed a brief self-administered questionnaire, the erectile function domain of

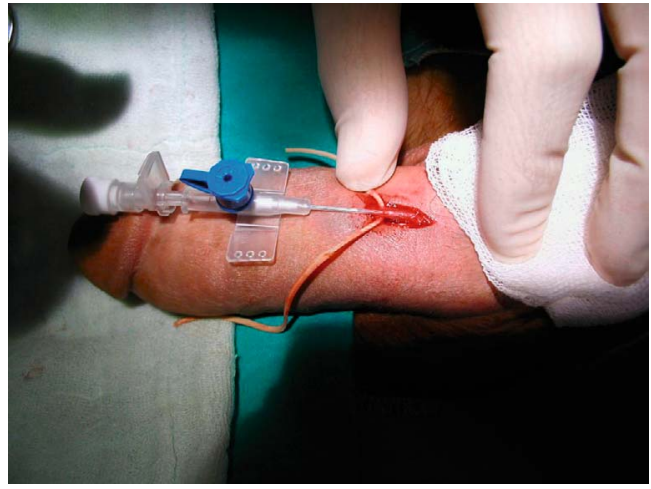

Figure $\mathbf{1 b}$. It was catheterized with angiocath.

the International Index of Erectile Function questionnaire (IIEF-EF). The severity of ED based on IIEF-EF domain score was classified as normal $(\geq 26)$, mild (22-25), mild to moderate (17-21), moderate (11-16) and severe (6-10).

The embolization procedure was performed in the angiography suite. After the patient prepared and draped in the supine position, penile block with prilocain was

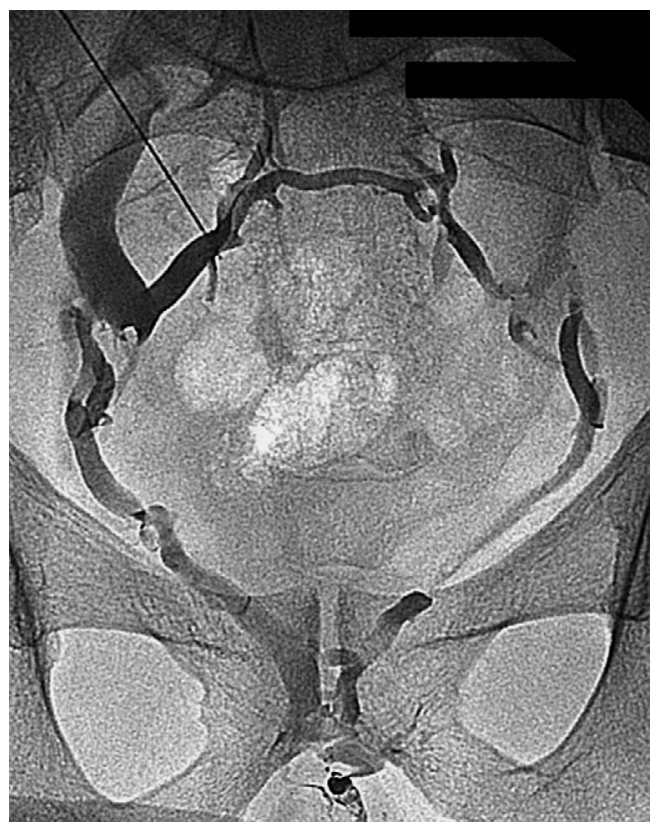

Figure 2a. Initial venogram after catheterization of deep dorsal vein showed significant venous leakage. 


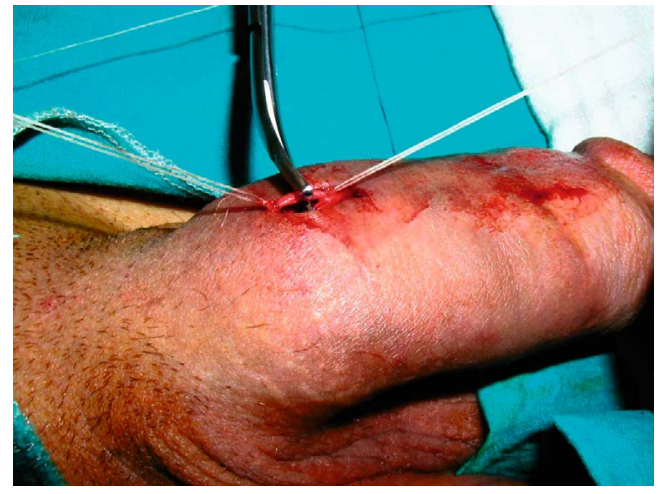

Figure 1c. After embolization incision was anatomically closed with absorbable suture material.

performed and papaverine was administered intracavernosally. A $2 \mathrm{~cm}$ penile dorsal midline incision was made at the mid penile level. The deep dorsal vein was isolated under Buck's fascia and catheterized with $21 \mathrm{G}$ angiocath (Figures 1a, b). Venography was performed to confirm the intravenous location and to demonstrate retropubic venous plexus and draining veins (Figure 2a). Residual contrast material in the venous

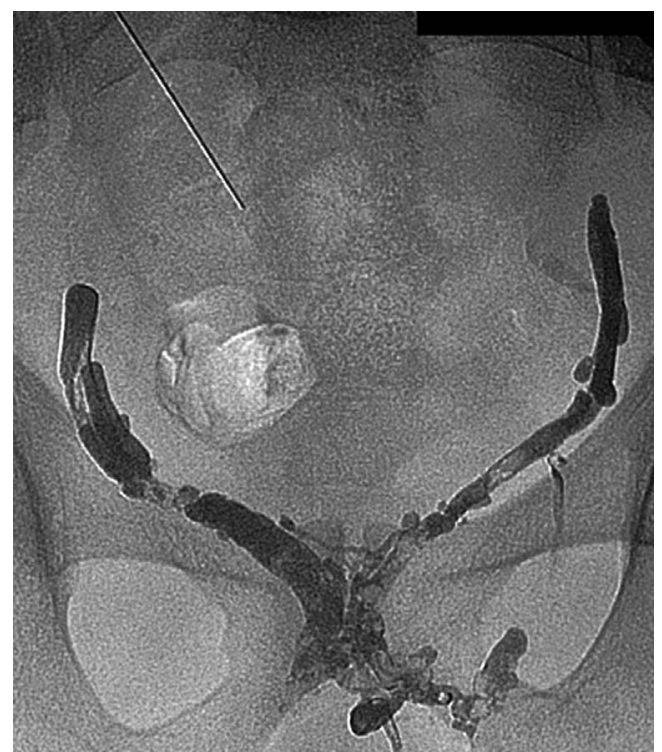

Figure 2b. N-butyl-2-cyanoacrilate (NBCA) and lipiodol mixture was administered under continuous fluoroscopic control. Occluded leaking veins were seen.

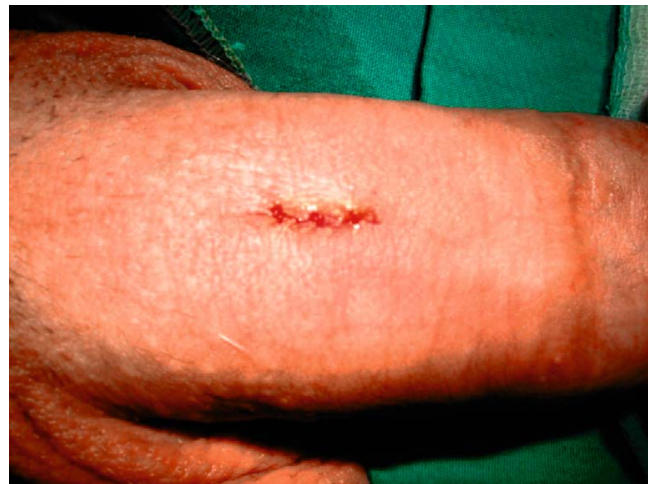

Figure 1d. The penile incision was anatomically closed with absorbable suture material.

structures and angiocath was washed with $5 \%$ dextrose solution. A mixture of NBCA (Histoacryl; Braun-Melsungen, Germany) and lipiodol (Lipiodol; Guerbet, France) was prepared in 1:5 ratio as reported by Peskircioglu et al. ${ }^{6}$ But based on the rate of venous filling on the initial venogram, the amount of lipiodol was increased or decreased in 4 and 3 cases, respectively. A volume of $5 \mathrm{ml}$ was injected antegrade into

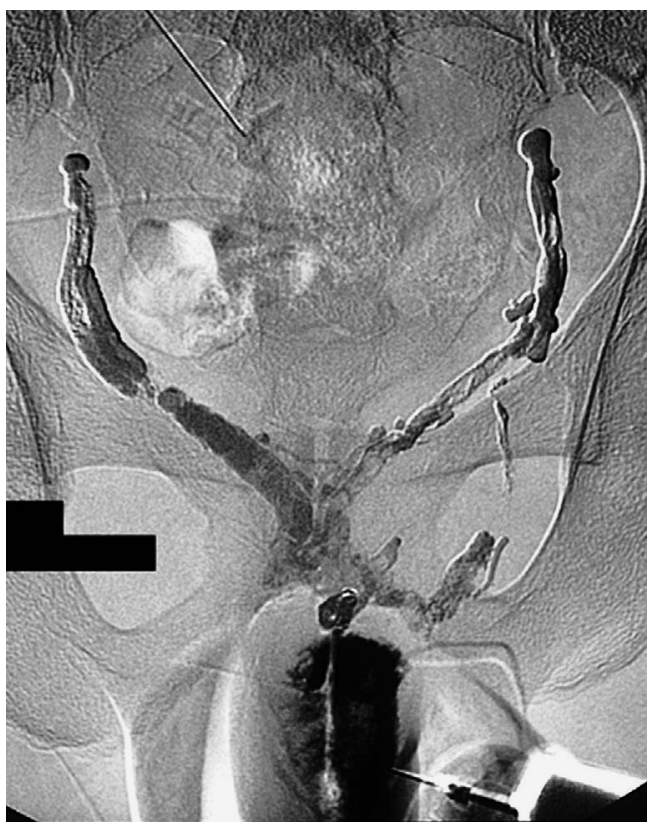

Figure 2c. Control cavernosography after embolization showed absence of venous leakage. 


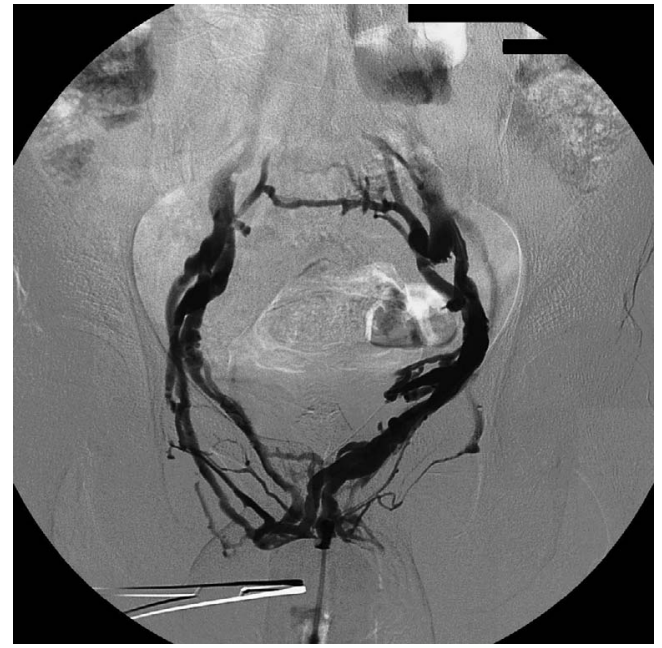

Figure 3a. Venogram showed significant and rapid venous leak to iliac veins.

the previously catheterized dorsal vein under the continuous fluoroscopic control. The occluded dorsal vein and its collaterals were visualized (Figures $2 b, c)$. If the mixture preferentially occluded the veins on one side, a repeat injection was performed for the remaining veins on the other side after the injection of a small bolus of $5 \%$ dextrose. If the venous leak to iliac veins was

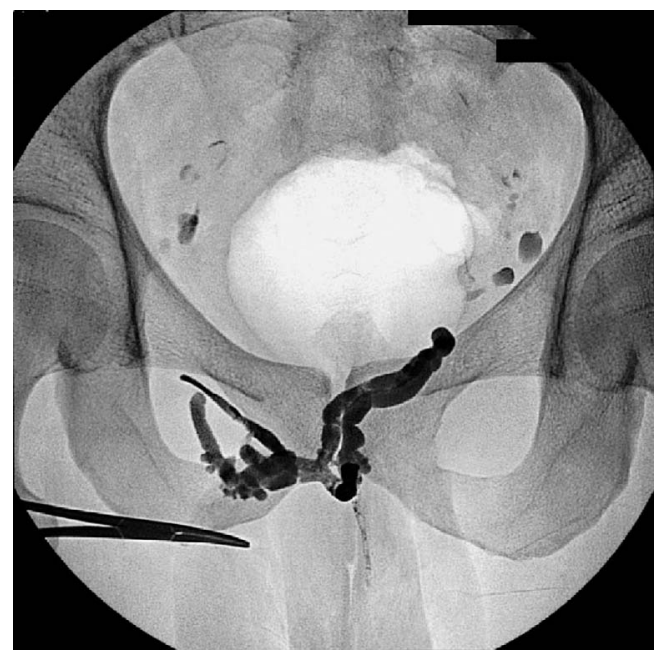

Figure 3c. Digital roentgenogram showed occluded leaking veins after embolization.

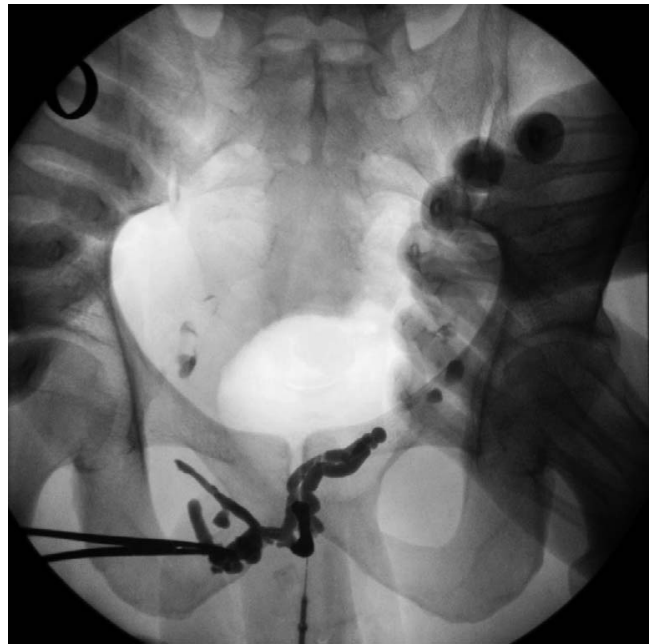

Figure $3 \mathbf{b}$. During the embolization both groins were manually compressed to prevent reflux of the mixture into the larger veins and avoid complications.

significant and rapid, the manual compression was applied on both groins (Figures $3 a, b, c)$. The penile incision was anatomically closed with absorbable suture material (Figures 1c,d) and an elastic bandage was applied to the penis. Compressive dressings were removed after 24 hours. Patients were reevaluated with IIEF-EF at 3 months and 1 year. No invasive examinations (cavernosography or cavernosometry) were performed during the follow-up period.

The preoperative, post-operative $3^{\text {rd }}$ and $12^{\text {th }}$ month IIEF-EF domain scores were compared with Wilcoxon's test and a $p$ value of less than 0.05 was regarded as statistically significant. These scores were also compared between patients with and without comorbidities using Mann-Whitney U test and a $p$ value of less than 0.05 was regarded as statistically significant.

\section{Results}

The patients, mean age $48.3( \pm 12.2)$ years, were evaluated in three groups as total, with associated comorbidities (diabetes 
Table 1. The mean preoperative, post-operative $3^{\text {rd }}$ and $12^{\text {th }}$ month International Index of Erectile Function questionnaire (IIEF-EF) domain scores in all groups $( \pm \mathrm{SD})$

\begin{tabular}{llll}
\hline IIEF-EF domain score & pre-op & post-op $3^{\text {rd }}$ month & post-op 12 $^{\text {th }}$ month \\
\hline Total [n:32] & $11.4 \pm 1,9$ & $20.1 \pm 3,4$ & $15.9 \pm 3,2$ \\
Comorbidity (+)[n:15] & $11.1 \pm 1,9$ & $18.9 \pm 3,8$ & $14.6 \pm 2,5$ \\
Comorbidity (-)[n:17] & $11.8 \pm 1,6$ & $21.5 \pm 2,2$ & $17.4 \pm 3,2$ \\
\hline
\end{tabular}

mellitus, coronary heart disease, hypertension, and smoking) and without associated comorbidites. The mean preoperative, post-operative $3^{\text {rd }}$ and $12^{\text {th }}$ month IIEF-EF domain scores in all groups were presented in Table 1.

Post-operative $3^{\text {rd }}$ month IIEF-EF scores were increased significantly in all groups $(p<0.001)$. But, there was a significant decrease in IIEF-EF scores at $12^{\text {th }}$ month when compared to that of $3^{\text {rd }}$ month $(p<0.001)$. In spite of this decrease at $12^{\text {th }}$ month, IIEF-EF scores were significantly higher than those of preoperative values $(p<0.001)$. In patients without comorbidities post-operative $3^{\text {rd }}$ and $12^{\text {th }}$ month IIEF-EF domain scores were significantly higher than those of patients with comorbidities $(p<0.04$ and $p<0.02$, respectively) (Figure 4).

Although in patients with comorbidities, IIEF-EF domain scores, at $12^{\text {th }}$ month were significantly higher compared to preoperative values; these patients were dissatisfied with the quality of erection. A penile prosthesis was implanted in a diabetic patient. Although the satisfaction at $3^{\text {rd }}$ month was decreased at $12^{\text {th }}$ month in patients without

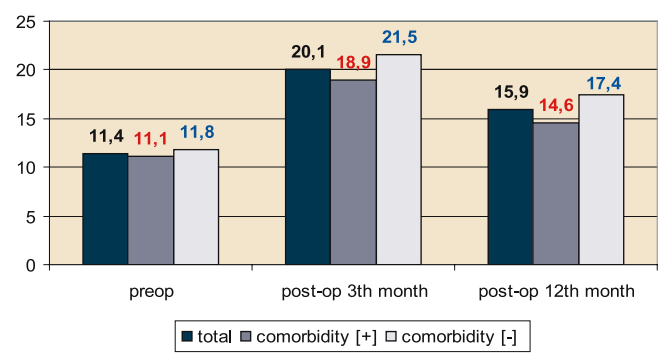

Figure 4. International Index of Erectile Function (IIEF) domain scores in all groups. comorbidities, enough erection to have intercourse with the help of PDE5 inhibitors was possible in 7 patients.

No complaints or complications were noted during the exposure of the deep dorsal penile vein in any patient. The $21 \mathrm{G}$ angiocath was inserted into the deep dorsal penile vein and successfully advanced in all patients. In two cases, a symptomatic pulmonary embolism complication occurred but that we treated conservatively (Figures $5 a, b, c, d)$.

Pelvic radiograms at 1 year follow-up were negative for contrast material.

\section{Discussion}

Erectile dysfunction could occur due to either arterial (inadequate inflow to meet the volume expansion of the dilated penile sinusoids) or venous (insufficient restriction of venous outflow to allow the retention of penile perfusion and to produce rigidity) causes. ${ }^{4}$ Venogenic erectile dysfunction is an important problem leading to impotence that could result from several pathophysiologic processes (large venous channels, degenerative changes or traumatic injury to the tunica albuginea, structural alterations in the fibroelastic components, insufficient trabecular smooth muscle relaxation, and acquired venous shunts). ${ }^{7}$ In order for a successful intercourse tonically contracted, flaccid penis needs some threshold amount of smooth muscle relaxation for conversion to the fully erect state with sufficient rigidity. ${ }^{6}$ If there is corporeal smooth mus- 


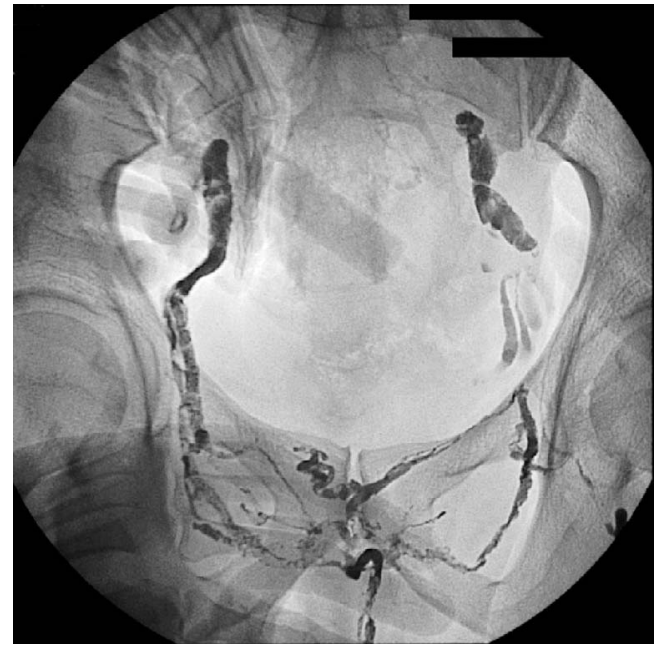

Figure 5a. In a patient with a significant venous leakage, mixture extended to both iliac veins despite the manual compression.

cle dysfunction preventing relaxation, it will result in the incomplete resistance to outflow of blood from the corpora, venous leakage and incomplete erection. ${ }^{6,8}$ Venous leakage is either due to functional causes like incomplete relaxation of trabecular smooth muscle or due to structural changes like fibrosis of the trabecular tissue, and less frequently venous leakage is originated by the presence of anomalous drainage through venous channels or through malfunctioning or ectopic veins which could be repaired. ${ }^{8}$

The penis is drained by three groups of veins: (1) superficial which primarily drains penile skin, but it could have anastomoses with the deep dorsal vein, (2) intermediate which consists of deep dorsal and circumflex veins and (3) deep which drains the deep cavernous tissue and consists of cavernosal and crural veins that are extensions of the emissary veins. ${ }^{9,10}$ The superficial dorsal vein runs superficially to the deep (Buck) fascia and these veins do not participate in erection. ${ }^{11}$ The venous drainage of the corpora cavernosa is mainly depend-

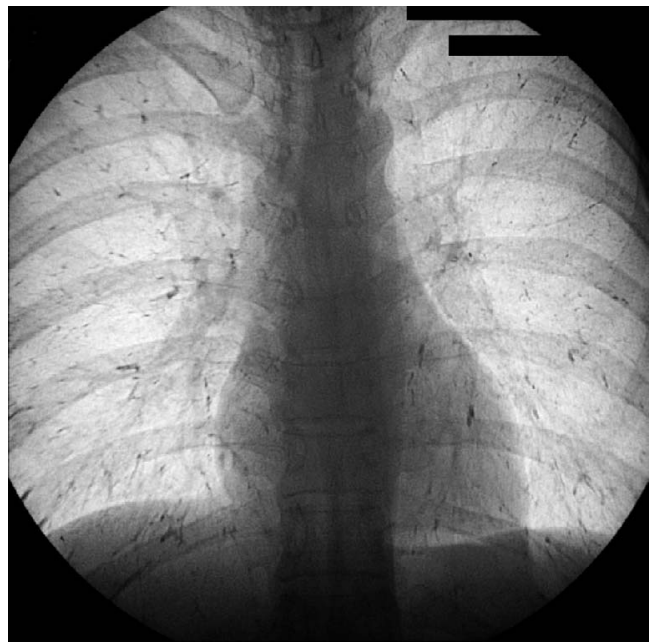

Figure 5b. Digital roentgenogram obtained immediately after the development of respiratory symptoms shows multiple tubular and round opacities alongside the pulmonary arteries in both lung zones.

ent on the deep dorsal vein that courses under the fascia penis, and it runs through the intracavernous sulcus to the prostatic plexus. ${ }^{12}$ The trabeculae of the corpus cavernosum drain into a system of subtunical venules that coalesce just beneath the $t u$ nica albuginea and form a number of veins transversing the tunica called emissary veins. Emissary veins usually drain into the circumflex veins on the outer surface of the tunica albuginea, and these circumflex veins in turn drain into the deep dorsal vein of the penis shaft between the dorsal arteries. ${ }^{9}$ The blood flowing from the circumflex veins to the deep dorsal veins is unidirectional. ${ }^{8}$

Currently, surgical ligation, radiological embolization, penile implants, self-injection therapy and pharmacotherapy are among the treatment options for venogenic ED. ${ }^{13}$ The main goal of the treatment in patients with veno-occlusive dysfunction is to occlude the venous outflow to provide a longterm improvement of erectile function. ${ }^{6,14}$ Several types of venous ligation surgery have been proposed for ED. Although the 


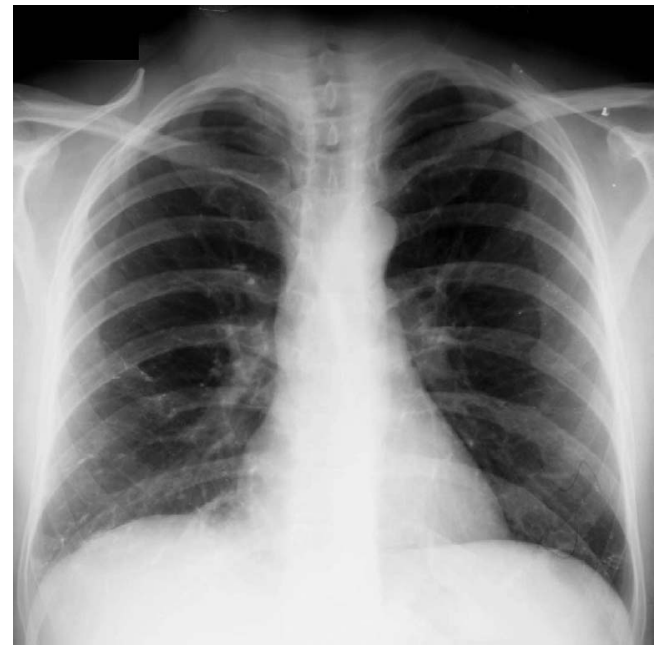

Figures $5 \mathbf{c}$. One month later, after the conservative treatment of the patient, control chest roentgenogram showed clearance of opacities.

ligation of penile veins to cure impotence has a long history, beginning in early 1900, recently renewed interest in venous surgery has increased due to the low acceptance rate of penile implants as the first line therapy, difficulties and expense of mixed pharmacotherapy, and high dropout rate (more than $50 \%$ ) for self-injection therapy in longitudinal studies. ${ }^{13}$ The surgical procedure has been expanded from the simple deep dorsal vein ligation to the extensive surgical exposure and vein ligation, excision, crural plication and spongiolysis performed alone or in combination. ${ }^{8}$ The dissection of the superficial dorsal vein and ligation or the dissection of the deep dorsal vein, with the occlusion of the circumflex veins, is reported to be the least invasive type of surgery. ${ }^{15}$ However, other more invasive procedures also require the ligation of the crural veins by means of perineal incision and dissection of the ischiocavernous muscles or the ligation of the crural portions of the corpora cavernosa. ${ }^{15}$ Due to the early development of collateral veins of the corpora cavernosa, the long-term success rate of such surgical treatments is approximately $25 \% .^{7}$ The

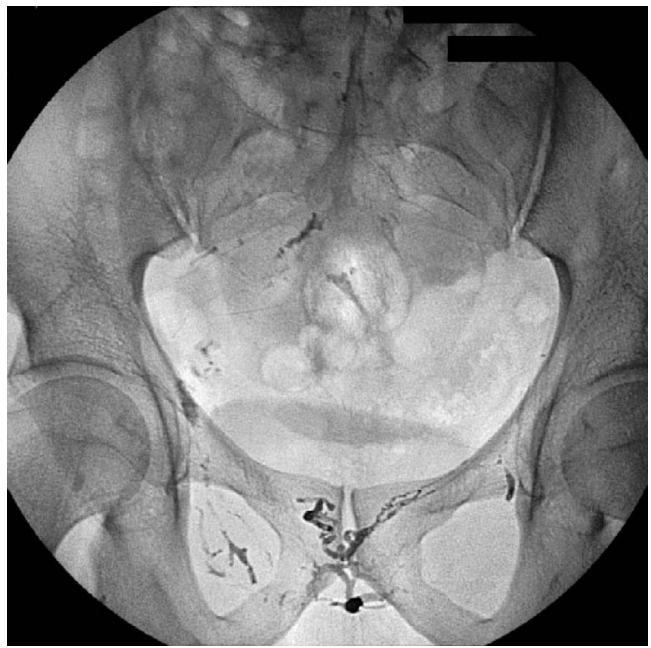

Figure 5d. Digital roentgenogram at $6^{\text {th }}$ month control showed still occluded periprostatic plexuses.

inability to ligate all of the defective veins because of tiny collaterals which cannot be seen intraoperatively and also the inability to ligate proximal veins like the retropubic venous plexus due to exposure problems are among the reasons for the failure of surgical ligation. ${ }^{7}$

In addition to various surgical and medical treatment options, radiological embolizations have been used for the treatment of venogenic erectile dysfunction with variable success rates. $2,6,7,12,16,17$ Various endovascular interventional procedures were developed for the treatment of venous erectile incompetence like embolization with surgical ligation, bilateral occlusion of crural veins with coils, percutaneous penile venous ablation with sclerosing agents., 7 Multiple veins can be embolized by an intraluminal procedure at once. ${ }^{7}$ DDVE with NBCA has been reported with encouraging results as a safe and effective procedure. ${ }^{6}$ NBCA is a tissue adhesive material that has been used for various vascular embolizations without any systemic side effects. 7,8 It has high adhesive force, instantly polymerizes upon contact with water and 
proteins in blood, and also its degradation rate is quite low which makes the occlusion long-lasting. ${ }^{18}$ Since it is non-opaque it is mixed with a radiopaque contrast media to observe during intervention under fluoroscopy. Lipiodol is used for this purpose due to its high hydrophobic feature which makes the hydrophilic ion species difficult to interact with NBCA monomers. ${ }^{17}$ Lipiodol also prolongs the polymerization time of NBCA. The embolization with NBCA and lipiodol is less expensive than a surgical procedure; the procedure is short and requires no hospitalisation. ${ }^{6}$ In all of our patients, it was possible to embolize all leaking veins responsible for anomalous venous drainage. Since embolic mixture is in a liquid form, even the tiny collaterals were embolized easily. Polymerization time can be controlled by the amount of lipiodol. Although we routinely mixed the NBCA with lipiodol in a ratio of $1: 5$, based on the rate of venous filling on the initial venogram, in four cases we decreased the amount of lipiodol in order to embolize most of the draining veins. Our pulmonary complications were among the ones where we decreased the lipiodol amount. In one of the pulmonary complication cases, a repeat injection had also been performed. Although our intention was to embolize most of the leaking veins, increasing polymerization time and in repeat injection cases increased risk of fragmentation and distal migration of NBCA and lipiodol mixture after the administration of dextrose bolus, leaded to the reflux of the mixture into the main and larger veins. The embolization of non-target organs or structures, like pulmonary arteries as in our cases, is a possible risk. If pulmonary embolism occurs, embolized NBCA causes an acute and chronic foreign body reaction in lungs. Lipiodol might produce lung damage due to breakdown into free fatty acids. ${ }^{17}$ The treatment of symptomatic pulmonary com- plications of glue embolization is primarily conservative as in our cases.

Since cavernosometry and cavernosography are invasive procedures, we did not perform them. For the further evaluation of our early and late results the validated IIEF was used. IIEF is a self-administered sexual function questionnaire that has demonstrated high specificity and sensitivity for detecting changes in erectile function associated with the treatment. ${ }^{19}$ It is reported to discriminate well between men with and without ED and has been used to assess the therapeutic efficacy and outcomes in patients with ED. ${ }^{19}$ The erectile function domain of IIEF pertains to sexual experience within the last 4 weeks consists of 6 questions designed to address sensitively and specifically relevant aspects of erectile function ${ }^{14,19}$ IIEF-EF domain could be used in clinical and research settings as a diagnostic aid for assigning degrees of ED severity. ${ }^{19}$

Statistically IIEF-EF domain scores in all of our patients were significantly increased at post-operative $3^{\text {rd }}$ month. There was a significant decrease in IIEF-EF domain scores in all groups at one year when compared to 3 rd month values. However, IIEF-EF domain scores were significantly higher than those of preoperative values. Despite this statistical significance, patients with comorbidities were dissatisfied with their quality of erection. Therefore, taking into consideration inherent possible complications and risks, we believe that DDVE should not be performed in patients with comorbidities despite the early good results. In venous surgery improved erections could be interpreted as converting a non-responder to oral or vasoactive injection therapy or a reduction in dose required for a successful intercourse. ${ }^{8}$ Even though the satisfaction level was decreased at one year in our patients without comorbidities, 7 of them had enough erection to have intercourse with the 
help of PDE5 inhibitors. Therefore, DDVE could be regarded as a procedure causing the improvement in erections in patients without comorbidities. Also, the synergism of penile venous surgery and oral sildenafil in treating patients with erectile dysfunction has been reported. ${ }^{20}$

In conclusion, our pelvic venoablation technique was effective and promising short-term. A limitation of this technique is that some patients are not candidates for this procedure due to comorbidites.

\section{References}

1. Benson CB, Vickers MA. Sexual impotence caused by vascular disease: diagnosis with duplex sonography. Am J Roentgenol 1989; 153: 1149-53.

2. Nakata M, Takashima S, Kaminou T, Koda Y, Morimoto A, Hamuro M, et al. Embolotherapy for venous impotence: use of ethanol. J Vasc Interv Radiol 2000; 11: 1053-57.

3. Friedenberg RM. Assessment of impotence with cavernosography. Radiology 1986; 161: 842.

4. Quam JP, King BF, James EM, Lewis RW, Brakke DM, Ilstrup DM, et al. Duplex and color Doppler sonographic evaluation of vasculogenic impotence. Am J Roentgenol 1989; 153: 1141-47.

5. Shafik A, Shafik I, El SO, Shafik AA. On the pathogenesis of penile venous leakage: role of the tunica albuginea. BMC Urol 2007; 7: 14.

6. Peskircioglu L, Tekin I, Boyvat F, Karabulut A, Ozkardes H. Embolization of the deep dorsal vein for the treatment of erectile impotence due to veno-occlusive dysfunction. J Urol 2000; 163: 4725.

7. Miwa $Y$, Shioyama R, Itou $Y$, Kanamaru H, Okada K. Pelvic venoablation with ethanol for the treatment of erectile dysfunction due to veno-occlusive dysfunction. Urology 2001; 58: 76-9.

8. Moncada I, Mulcahy J, Cabello R, Hernández C. Surgery for erectile dysfunction: current indications and future perspectives. EAU Update Series 2004; 2 January 1.

9. Prieto D. Physiological regulation of penile arteries and veins. Int J Impot Res 2008; 20: 17-29.
10. Hsu GL, Hsieh CH, Wen HS, Kang TJ, Chiang HS. Penile venous anatomy: application to surgery for erectile disturbance. Asian J Androl 2002; 4: 61-6.

11. Malhotra CM, Balko A, Wincze JP, Bansal S, Susset JG. Cavernosography in conjunction with artificial erection for evaluation of venous leakage in impotent men. Radiology 1986; 161: 799-802.

12. Courtheoux P, Maiza D, Henriet JP, Vaislic CD, Evrard C, Theron J. Erectile dysfunction caused by venous leakage: treatment with detachable balloons and coils. Radiology 1986; 161: 807-9.

13. Cakan M, Yalcinkaya F, Demirel F, Ozgunay T, Altug U. Is dorsale penile vein ligation (DPVL) still a treatment option in veno-occlusive dysfunction? Int Urol Nephrol 2003; 35: 529-34.

14. Sarramon JP, Malavaud B, Braud F, Bertrand N, Vaessen C, Rischmann P. Evaluation of male sexual function by the International Index of Erectile Function after deep dorsal vein arterialization of the penis. J Urol 2001; 166: 576-80.

15. Bertolotto M, Serafini G, Savoca G, Liguori G, Calderan L, Gasparini C, et al. Color Doppler US of the postoperative penis: anatomy and surgical complications. Radiographics 2005; 25: 731-48.

16. Bookstein JJ, Lurie AL. Transluminal penile venoablation for impotence: a progress report. Cardiovas Inter Rad 1988; 11: 253-60.

17. Kutlu R, Soylu A, Alkan A, Turker G. Pulmonary embolism after penile deep dorsal vein embolization with n-butyl-2-cyanoacrylate and lipiodol mixture. Eur J Radiol Extra 2004; 49: 103-6.

18. Oowaki H, Matsuda S, Sakai N, Ohta T, Iwata H, Sadato A, et al. Non-adhesive cyanoacrylate as an embolic material for endovascular neurosurgery. Biomaterials 2000; 21: 1039-46.

19. Cappelleri JC, Siegel RL, Osterloh IH, Rosen RC. Relationship between patient self-assessment of erectile function and the erectile function domain of the international index of erectile function. Urology 2000; 56: 477-81.

20. Wen HS, Hsieh CH, Hsu GL, Kao YC, Ling PY, Huang HM, et al. The synergism of penile venous surgery and oral sildenafil in treating patients with erectile dysfunction. Int J Androl 2005; 28: 297303. 